\title{
Migração de aves na região do cerrado do Brasil Central
}

\section{Introdução}

A movimentação de animais sempre foi um fenômeno que atraiu a atenção do homem. No início, como caçador/coletor, necessitava seguir alguns animais de porte em seus movimentos diários e estacionais para garantir alimento. Outras vezes, já com uma agricultura em desenvolvimento e, portanto, mais sedentário, aproveita-se do aparecimento de um recurso de caça abundante em uma fase do ano. Essa dependência direta de um recurso móvel ainda existe hoje em algumas poucas sociedades humanas primitivas. Todos estes fatores atuaram sobre o homem fazendo com que ele criasse mitos e se interessasse pelas movimentações de animais silvestres. E dentre estas movimentações ressaltam-se, pela sua extensão, visibilidade e número de indivíduos envolvidos, as migrações de aves. Os primeiros registros escritos relatando migrações de aves estão no Velho Testamento e mitos agrícolas da história clássica estão relacionados com o aparecimento e desaparecimento estacional de aves na área de cultivo.

O presente trabalho procura dar uma visão geral sobre o conhecimento atual das migrações de aves e particularizá-las na área do cerrado do Brasil Central.

\section{Migrações de aves}

A migração de aves é um movimento estacional de uma população ou parte de uma população do seu local de reprodução para uma área de invernada com retorno ao ponto de partida na próxima estação reprodutora. Dentro deste conceito básico não há qualquer referência à distância percorrida na movimentação. Esta não é sempre de grande magnitude, como, por exemplo, na Serra do Mar, onde várias aves migram desde altitudes mais altas para a base das montanhas, percorrendo poucos quilômetros nesta migração.

Como em outros fenômenos biológicos das aves, a migração é controlada por hormônios com origem na hipófise. Estes hormônios são liberados pela percepção da diferença entre a extensão do dia e a extensão da noite, fato de grande importância nas regiões temperadas e subtemperadas, ou pelo aparecimento/desaparecimento de frutos, folhas, etc., em áreas tropicais, ou com clima semi-árido, como a caatinga nordestina.

Estes, entretanto, são estímulos que ocorrem hoje, mas, evolutivamente, as diversas espécies ou populações de aves migratórias iniciaram seus movimentos em pequena escala, como resposta à falta estacional e transitória de alimento, retornando com a volta do alimento desaparecido. Lentamente, através da seleção natural, gerações seguintes foram incorporando ao patrimônio genético da populaçãolespécie estes padrões de movimentos controlados a partir da hipófise.

Hoje, as aves não esperam a redução de alimento para migrar. Muitas vezes iniciam sua migração durante o maior período de oferta alimentar no local de reprodução. Devido aos mecanismos hormonais de controle, desenvolvidos ao largo de miIhares de anos, elas "sabem" qual é a hora exata de começar seu movimento com o melhor estado nutricional possível. 
Isto nos leva a um outro questionamento: como as aves em migração orientam-se para chegar aos locais de invernada ou voltar aos de reprodução, separados em poucos quilômetros, como no caso das aves da Serra do Mar, ou por toda a extensão de Terra, como no caso do Trinta-réis-ártico, Sterna paradisaea, que migra dos mares do Pólo Norte para o Pólo Sul? Esta pergunta ainda terá que esperar alguns anos antes de receber uma resposta direta. Sabe-se, porém, que as migrantes diurnas são capazes de determinar sua posição pela do Sol, e são capazes, também, de perceber o eixo magnético da Terra e características geográficas marcantes e, ain$\mathrm{da}$, de perceber as diferenças, mínimas, existentes entre a força de gravidade nas diversas latitudes. As aves que migram à noite, e aí incluem-se a quase totalidade dos pássaros (Passeriformes) normalmente diurnos, orientam-se basicamente pelos mesmos fatores, só que, ao contrário das migrantes diurnas, que se orientam pela posição do Sol, mas se guiam através das estrelas e constelações.

Logo após o nascimento, os filhotes das aves migratórias possuem, em seus gens, a informação que necessitam para se orientar e migrar. Em várias espécies, esta informação é suficiente para, sem ajuda dos pais ou de outras aves adultas, os jovens chegarem ao local de invernada. Este é o caso, por exemplo, do batuiruçu, Pluvialis dominica, que se reproduz na tundra ártica e migra para os campos do Rio Grande do Sul, Argentina e Uruguai; os filhotes partem antes dos pais, em bandos, usando inclusive uma rota de migração diferente daquela dos adultos, chegando sem problemas à área de invernada. Entretanto, este não é o caso de todas as aves, em que normalmente, os jovens irão migrar assim que chegar o período hormonalmente determinado. Mas só uma pequena proporção irá movimentar-se para a área de invernada, chegando ali por mero acaso, necessitando, neste caso, também de um aprendizado, fornecido pelos pais que já migraram anteriormente, como, por exemplo, o Trinta-réis-boreal, Sterna hirundo, que chega a toda costa do Brasil, e de várias outras espécies.

\section{Migrações de aves na região do cerra- do do Brasil Central}

Das 1.580 espécies catalogadas para o Brasil sabemos que 119 são migratórias. É quase certo que muitas outras, hoje consideradas como sedentárias, possuem populações migratórias ou até mesmo sejam totalmente migratórias.

Das migratórias, podemos separá-las nas espécies da América do Norte, que passam pelo Brasil ou aqui invernam, como o batuiruçu; nas espécies que reproduzem-se no sul do Brasil è no Cone Sul, migrando ou invernando no centro e no norte do Brasil; e nas espécies que reproduzem-se e invernam dentro do Brasil, como as aves migratórias da Serra do Mar.

Na região do cerrado do Brasil Central, nós vamos encontrar várias formas de vegetação, sendo as principais o campo limpo, formado por uma imensa porcentagem de gramíneas; o cerrado, formado por gramíneas e árvores baixas; o cerradão, formado por árvores altas e ausência de gramíneas; a mata seca ou mata de interflúvio, formada por árvores de grande porte em áreas de afloramento calcário; e mata de galeria ou ciliar, formada por árvores de origem amazônica ou da Mata Atlântica, que crescem às margens dos rios e riachos da região.

Dentro de tal diversidade vegetacional é lógico esperar-se uma grande diversidade de aves. Toda a região, entretanto, possui uma nítida estação seca que se estende de maio a setembro e uma estação chuvosa nos outros meses. Na parte sul do Brasil Central há uma forte influência de frentes frias durante o início da época seca, estendendo-se, as baixas temperaturas, em algumas regiões altas, até meados de agosto.

Como resposta a essa variabilidade estacional bem marcada de água disponível e a queda de temperatura, cada forma de vegetação possui mecanismos biológicos próprios que a permite sobreviver à falta de recursos. Esta resposta da vegetação à época seca e fria, principalmente, acarreta uma redução sazonal de alimentos para as aves, seja pela nãofloração, não-frutificação ou pela perda de folhas. É de se esperar, então, que as aves possuam, também, alguns mecanismos para sobrevivência e entre estes está a migração. Aqui ela pode ser de grande amplitude, para fora da região, ou entre formas de vegetação distintas, como, por exemplo, entre o cerrado e a mata ciliar ou cerradão. Na prática, poucos casos são conhecidos, entretanto, faltam os estudos que permitam detalhar estes movimentos. Podemos imaginar, todavia, o problema enfrentado por beijaflores do cerrado diante da ausência ou redução estacional de flores e insetos - seus alimentos principais. O beija-flor-chifrinho-dourado, Heliactin cornuta, aparenta mover-se de uma região a outra no início do período seco e o beija-flor-de-canto, Colibri serrirostris, torna-se mais presente nas bordas da mata ciliar.

No final da estação chuvosa e início da seca, passam pelo cerrado em direção ao norte ou permanecem nesta região aves que se reproduzem no sul do Brasil ou da América do Sul. Mesmo dentro de cidades podemos perceber os grupos de siriri, Tyrannus melancholicus, aves que normalmente são solitárias. Estão migrando para a Bacia amazônica e para o Norte da América do Sul. 
As matas da região recebem alguns sabiás, em especial o sabiá-poca, Turdus amaurochalinus, e o sabiá-ferreiro, Turdus nigriceps, para a época de invernada, provando novamente que a redução estacional de alimento é diferente dentro dos diversos tipos de vegetação.

É no final da seca e início das chuvas que a região do Brasil Central assiste a mais ėspetacular migração de aves. De meados de agosto a outubro movem-se para o sul as aves que invernam ao norte do Rio Amazonas, das quais o exemplo mais visível é a tesourinha, Muscivora tyrannus; dirigem-se para as áreas de reprodução. Movem-se junto a elas, as aves do Hemisfério Norte, que dirigem-se à América do Sul para invernada. Passám pelo Brasil Central maçaricos, batuíras e andorinhas, em grandes bandos.

Todo este movimento, esta migração, mecanis- mo que permitiu a sobrevivência de várías espécies por milhares de anos, que encantou e encanta o homem, encontra-se ameaçado, hoje em dia, devido a alterações desmedidas do ambiente, pela poluição dos pontos em que as aves migratórias concentramse para buscar alimento ou por massacres destas aves nos mesmos locais.

Temos assistido à redução do número de algumas aves migratórias devido ao mau manejo dos recursos naturais feito pelo homem, o qual aparentemente esqueceu-se que vivemos em um planeta finito, cujos recursos existem para utilização racional sustentada e não com propósitos imediatistas.

Mas, cabe somente a nós decidir se as aves migratórias manterão seu ciclo infindável de movimentação ou se chegou o momento onde elas não poderão mais existir na face da Terra. 


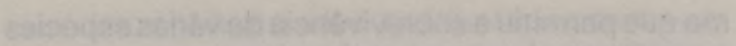

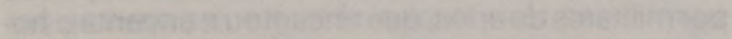

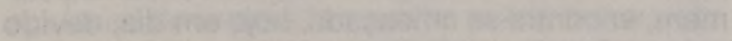

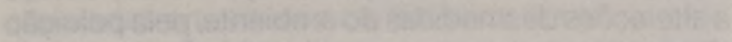

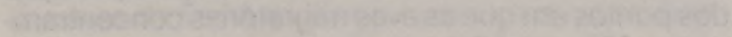

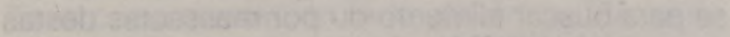

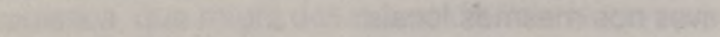

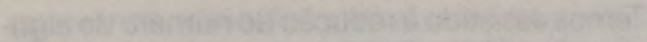

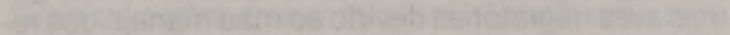

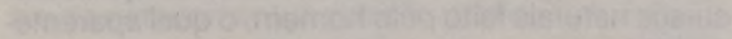
aiky

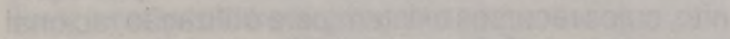

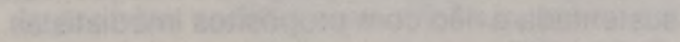

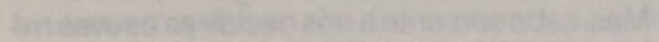

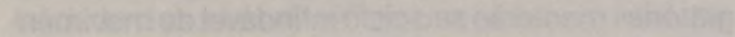

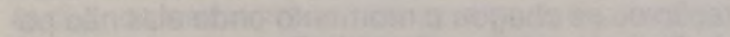

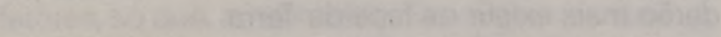

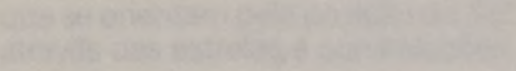
berint -

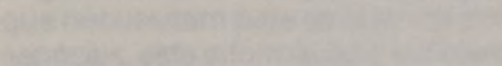

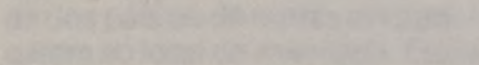

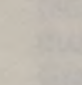

